\title{
Code-switching in Botswana's ESL Classrooms: A Paradox of Linguistic Policy in Education
}

\author{
Ambrose B. Chimbganda \& Tsaona S. Mokgwathi \\ Department of Communication and Study Skills, University of Botswana \\ P.O. Box 0022, Gaborone, Botswana
}

Tel: 267-71-840-268; 267-71-702-662Ｅ-mail: chimbga@mopipi.ub.bw; mokgwathit@mopipi.ub.bw

Received: November 28, 2011

Accepted: January 12, $2012 \quad$ Published: April 1, 2012

doi:10.5539/ijel.v2n2p21

URL: http://dx.doi.org/10.5539/ijel.v2n2p21

\begin{abstract}
Code-switching in the classroom is known to take place across a wide range of subjects in multilingual settings in Africa and, indeed, throughout the world; yet it is often regarded pejoratively by some educational policy makers. This article looks at code-switching (CS) in Botswana's senior secondary schools within the context of the country's language-in-education policy, which states that English is the official language of learning and teaching while Setswana is the national language used for identity, unity and national pride. The data are derived from an ethnographic study conducted at four high schools in the north-eastern part of the country, which is uniquely multilingual. The findings indicate that code-switching from English to Setswana is quite prevalent in content subjects, and is used as a pedagogic resource to clarify the knowledge of the subject matter and to reduce the social distance between the teacher and learners. From the findings, it is suggested that code-switching in ESL classrooms in Botswana should be recognized not only as a communicative strategy for instruction, but also as a way of creating classroom warmth and friendliness.
\end{abstract}

Keywords: Code-switching, Alternation, Target language, ESL, Bilingual, Multilingual, Diglossic, Exoglossic, Lingua franca, Fuctionality

\section{Introduction}

In the field of education, code-switching is a widely observed phenomenon especially in diglossic communities which have two or more distinct languages, one of which is a superimposed language used officially for public affairs and the others for normal, everyday communication. In Botswana, like in many other former British colonies, classrooms display symptoms of competing linguistic identities (Garafanga, 2001; Sebba-Wootton, 1998; Stroud 1998), with each local language trying to carve out a legitimate space on a core-periphery relationship with the 'official' language. The challenge of this linguistic fluidity in the classroom is often exacerbated by ruling political elites and their education administrators who reproduce structural approaches to code-switching that prevent native languages from being used for teaching purposes, without carefully considering the functionality of code-switching in the classroom or the linguistic competence of both teachers and pupils in the target language.

In the context of Botswana, besides the 1977 commission on education, the government undertook a second National Commission on Education (NCE 2) in 1993 which was tasked to review the education system and to develop a 'new' system that would enable the country to meet the challenges of the $21^{\text {st }}$ century. The findings of the commission are interesting in that English was recommended to be used as the medium of instruction from Standard One by 2000. Here, the authors of the commission seem to think that code-switching occurs in classrooms because learners are exposed to English at a relatively late stage, having received their early education in Setswana. In the commission's view, this delays the learners' acquisition of English which is used as the language of learning for their entire education system up to the university level.

Furthermore, the 1994 report also seems to have been influenced by the 'immersion' theory and current applications of communicative techniques which suggest that communicating completely in the target language is a sure way of gaining maximum input (Macaro, 2001); and that code-switching adulterates the acquisition of the second language (Gabrielatos, 2001). Cook (2002, p. 333) similarly notes that code-switching in multilingual classrooms can create problems if there is no common language for all the students and if the teacher is not 
competent enough in the mother tongue of the learners. In this scenario, code-switching will not serve its intended purpose.

While proponents of the 'pure language norm', that is, those who believe in the use of the target language (TL) for learning and teaching may have persuasive arguments, the main weakness of their approach is that they appear to be influenced by traditions of prescriptivism and the deficit hypothesis, the latter which views an exoglossic language as inherently superior to the native languages and therefore must be imposed on the indigenous speech communities. This approach fails to appreciate the fact that classrooms are usually compound bilingual spaces in which code-switching is inevitable (Cook, 2001; Liebscher \& Dailey-O'Cain, 2005; van der Meij \& Xhao, 2010). Jorgensen (2005) argues that as long as teachers and students have access to different languages, they are likely to employ either of them in a particular situation.

In the context of a classroom setting, the reality is that the existence of two or more languages does not necessarily mean that they are distinct and separate in their function. Quite often, they are intertwined to the extent that they form a mutually supportive role by exploiting the students' L1 in order to increase their understanding of the L2. If code-switching is viewed from this functional perspective, then language alternation does not necessarily indicate a lack of competence in any of the languages concerned, but results from complex bilingual skills (Auer, 1998; Kieswetter, 1995; Myers-Scotton, 1993). Because of the underlying value of code-switching, Canagarajah (2005) maintains that "many scholars are now moving to the position that code-switching may constitute a valid medium of communication in its own right and that we should give this some attention in our pedagogy" (p. 941).

\section{Conceptual definition of code-switching}

In this article, the researchers argue for a wider interpretative meaning of code-switching than is normally given by offering a vocal critique of prevailing notions. The usual structural definition of code-switching is that it is the alternative use of at least two languages, or varieties of the same language, one of which is an 'on-stage' or 'matrix' language, which is the target language and the other is a 'back-stage' or an 'embedded' language which is the home language of the learners (Myers-Scotton, 1993). Milroy and Muysken (1995) simply define code-switching as "the alternative use by bilinguals of two or more languages in the same conversation" (p.7).

In the same vein, Numan and Carter (2001) define code-switching as "a phenomenon of switching from one language to another in the same discourse" (p. 275); while Gumperz (1982) refers to it as "the juxtaposition within the same speech exchange of passages of speech belonging to two different grammatical systems or subsystems" (p. 59). Myers-Scotton (1993) similarly describes code-switching as a cover term to mean "alternations of linguistic varieties within the same conversations" (p. 1). A frequently cited typology of code-switching is intra-sentential and inter-sentential, with the former occurring within the clause or sentence, while the latter taking place at the clause or sentence boundary.

As can be seen from the above characterization of code-switching, structural approaches tend to focus on the surface aspects, the 'what' of a language alternation and the regularities of the switches. Here, the main focus is to identify grammatical aspects such as syntactic and morpho-syntactic constraints. Yet code-switching can be viewed from a sociolinguistic standpoint, which focuses on the 'why' and 'how' part, that is, the functional aspect which tries to identify the reasons for, and effects of, code-switching. In this regard, sociolinguistic research plays a crucial role in making us understand the functional element of code-switching. Working along this paradigm, Adendorff (1996) defines code-switching as a "communicative resource which enables teachers and students to accomplish a considerable range of social and educational objectives" (p. 389).

The sociolinguistic approach extends the frontiers of our knowledge about code-switching, and the first point is that in any multilingual country the prevailing political ideology creates or limits the space for code-switching. Gal (1989) contends that code-switching is done within the prescribed "political economic position in the long-standing system of core-periphery relations" (p. 357) between "those in control of institutions who may want to reject and devalue other people who want to gain access to material resources" (p. 352).

The chilling point that Susan Gal raises is that where code-switching takes place, groups of people may be in competition over scarce symbolic and other resources. The different language alternation, such as using the second language, crossing and resorting to the lingua franca may operate across lines of social differentiation as a way of co-opting linguistic resources of the powerful in a battle to carve out a legitimate space for the voices of those on the lower echelons of the social ladder. Stroud (2004) echoes this point by referring to the issue as a "we-they" problem, in which bilingual speakers make use of code-switching, crossing, loans and other linguistic phenomena in order to construct inclusive or exclusive categories of speakership that serve to negotiate access to symbolic and material resources. 
Assumptions of this nature, however, may be simplistic in the context of Botswana where English is not necessarily associated with a clearly definable class or race that is responsible for the reproduction of the language, unlike in neighbouring South Africa, Zimbabwe or Kenya. On the contrary, Botswana's elite are heterogeneous and are often cleaved along economic, educational, ethnic and regional identities. The relative economic success of the country, with wealth from diamond sales filtering through (albeit minimally) to the village level, pulls down some of the social boundaries that influence code-switching.

What appears to determine code-switching in the country, and for that matter in the classroom, is the particular context or to use Bourdieu's (1977) term, "linguistic markets" in which the utterances are produced. Much of the classroom discourse generally fits Bourdieu's (1977) observation that "we learn that the efficacy of a discourse, its power to convince, depends upon the authority of the person who utters it, or what amounts to the same thing, on his 'accent' functioning as an index of authority" (p. 653). Overlaying this complex pattern of code-switching in Botswana is the influence of transportable American and South African English varieties through television, an aspect which catalyzes together with gender and age as well as the urbanity and rurality of the speakers to create multiple identities that can rapidly code-switch depending on the context, topic, ethnic or social class of the interlocutors.

Over and above the complex issues that influence code-switching in Botswana, the researchers accept Butler's (1997) notion of 'performativity', which suggests that the essence of all languages is to try to bring together different social identities within a certain space of regulated semiotic options. This idea removes code-switching from structural norms which focus primarily on the forms in which code-switching takes place and situate it within the realm of functionality. Butler's (1997) approach suggests that code-switching is a multilayered, temporal and discursive process by which identities are produced and heard, maintained or discarded; and speakership rights and rights of reception are granted some legitimacy.

Taking cues from this notion, code-switching in this study is taken to mean it is a communicative strategy of redeploying the linguistic resources available to bilingual speakers in a particular situation in order to enhance meaning and understanding of the subject matter. Trudgill's (2000) observation is that "speakers switch to manipulate or influence or define the situation as they wish and to convey nuances of meaning and personal intention" (p. 105). The use of code-switching as a way of clarifying meaning is reiterated by Eldridge (1996) who maintains that "messages are reinforced, emphasized, or clarified where the message has already been transmitted in one code, but not understood" (p. 306). The idea is that by repeating the utterance in the native tongue, the learner is likely to understand more easily the meaning of the constitutive message.

\section{Research problem}

As mentioned earlier in this article, there is a paradoxical situation in the language policy of Botswana. On one hand the position of the government is that English is the official language which is used for teaching and learning throughout the secondary school system up to university; and on the other hand Setswana is the national language which, to all intents and purposes, is the de facto lingua franca in many spheres of private and public life. Instead of giving legitimacy to this naturally occurring language dualism, advocates of the use of English prescribe it as the sole language of learning and teaching.

This 'purist' approach somehow equates code-switching with "linguistic deficiency" (Kamwangamalu, 2000, p. 60 ) and based on this premise, the country's political power players and education officials deny or at the very least turn a blind eye to the existence of code-switching in the classroom (Arthur, 2001). Available literature also suggests that in some cases code-switching is considered "irritating" (Lawson and Sachdev, 2000, p. 1345). The point, here, is that even if it were to be established that code-switching slows down the acquisition of the second language, Skiba (1997) notes that in the circumstances where it is used due to the lack of competence in the target language, it still fulfils the vital role of speech continuity instead of interfering with communication.

If for a moment we are to accept that advocates of the 'purist' approach to code-switching have genuine misgivings about its usefulness, research elsewhere (e.g. Adendorff, 1993; Akindele and Letsoela, 2001; Arthur, 2001; Gila, 1995; Hussein, 1999; Lawson and Sahdev, 2000) suggests that code-switching thrives in many classroom situations. In Botswana, like in many other bilingual societies, code-switching has been reported to be pervasive, in spite of the fact that the official language policy is against it (Letsebe, 2002; Mafela, 2009). Interestingly, code-switching has also been seen to occur between other indigenous languages in various parts of Botswana where Setswana is not the home language of the majority of the learners (Molosiwa, 2006). In this regard, Nyati-Ramahobo (2004) notes: "in practice teachers actually code-switched between Setswana and English throughout the primary and secondary school level....Practice further indicated that in the North East District, Ikalanga continued to be used as an informal medium of instruction" (p. 43). 
These studies by indigenous researchers cast doubt on the wisdom of discouraging authentic code-switching in the classroom. In order to deepen the researchers' understanding of the complex nature of code-switching in schools, this study investigated the extent to which code-switching is used in teaching and learning the various subjects of the senior secondary school curriculum. The researchers' approach is in contrast with some of the previous studies in the country which tended to look at code-switching as a piecemeal and isolated phenomenon. To maintain the focus of the study, the following research questions were posited:

1) How prevalent is code-switching across the different subject disciplines?

2) Is the use of code-switching in teaching and learning at senior secondary school due to a lack of proficiency in English by both learners and teachers?

3) Is code-switching consistent with the practical realities of the classroom situation?

4) Is the use of code-switching in teaching and learning at senior secondary school undermining Botswana's language policy in education?

\section{Methodology}

\subsection{Site}

The study was conducted at four senior secondary schools (two urban and two semi-urban) which are located in the north-eastern part of Botswana, where there is more linguistic heterogeneity than in any other part of Botswana. In this region, in addition to Setswana which is the lingua franca of the country, the community speaks Ikalanga, a language which is genealogically related to Shona spoken in Zimbabwe and Ndebele, a tributary language of Zulu spoken in the western part of Zimbabwe. The four senior secondary schools offer grade eleven and twelve leading to the Botswana General Certificate of Secondary Education (BGCSE), which is similar to the University of Cambridge International General Certificate of Secondary Education (IGCSE).

\subsection{Subjects}

There were 94 teachers involved in this study (41 male and 53 female) and 2, 300 learners (1,035 male and 1265 female). The teachers were selected 'purposefully' as a microcosm of the larger population in order to obtain insights into the prevalence of code-switching in different subjects. However, since the procedure of sampling relied on 'convenience', it is possible that the teachers in this study might not be completely representative of the global population, more especially as it is known that individual human beings have unique characteristics.

The skewed gender imbalance in favour of females reflects the general population composition in Botswana, and all the teachers involved in this study were Botswana citizens, many of whom speak English with a Bantu influence. A characteristic that typifies the participants is that ninety one per cent (91\%) of the teachers held a first degree and a professional teaching qualification such as a postgraduate diploma in education, while $9 \%$ had a Masters degree. The vast majority of the learners $(99,33 \%)$ spoke Setswana either as a mother tongue or as a second language and the remainder spoke other African languages. The learners' age ranged from $16-24$, with $78 \%$ of them between $17-18$ years.

\subsection{Process}

The study is ethnographic in nature, which required "extensive time on site to systematically observe, interview, and record processes as they occur naturally at the selected location" (McMillan \& Schumacher, 1993, p. 405). Consistent with this approach, the study involved a prolonged engagement with the subjects, which involved observing and audio-taping the lessons. Prior to this, the researchers had emphasized to the participants the confidentiality of the information and how it would influence the language policy on education in the country. Altogether 197 lessons were recorded; 20 of whom were purposefully selected and transcribed verbatim from Biology, Home Economics, History and English. The choice of these subjects was influenced by their representativeness, that is, the need to study one of the science subjects, one practical subject, one human science and the target language.

The transcribed biology lesson on filtration (grade 11) was taught by a female teacher at an urban school; the home economics lesson on design elements and principles (grade 11) was taught by a female teacher at a semi-urban school; the history lesson on the colonization of the South African Cape by the Dutch (grade 12) was taught by a male teacher at an urban school; and the English language lesson on a comprehension passage entitled Man and Animals (grade 12) was taught by a male teacher at a semi-urban school. The attempt to maintain an equilibrium between urban and rural schools and between male and female teachers was meant to sustain the balance between the different groups. 


\subsection{Data analysis}

The procedure of analyzing the data followed Hymes' (1974) mnemonic speaking model which was used to identify whether code-switching occurred at certain stages of the discourse or throughout the course of the lesson. Each lesson was divided into three main parts, referred to by Hymes (ibid) as a sequence act, that is, 'discourse initiation', 'development' and 'discourse closure'. The model also allows for the identification of code-switching as a speech act in order to determine whether it performs an educational or an affective function, such as building solidarity with the learners in order to foster class participation.

The transcriptions consisted of the utterances of the teachers and the learners, which were reflectively analysed in order to interpret the communicative intentions of the switches from the target language into the native language of the learners. In this study, the learners' utterances were limited because they were usually passive learners who were only occasionally invited by the teacher to participate. The limited voice of the learners appears to have resulted from using the traditional lecture method, which is authoritarian in nature and inclined to the Confucian approach which regards teachers as fountains of knowledge instead of being facilitators who allow pupils to reconstruct knowledge more or less independently (Ni, 2007). Besides the transcriptions, the researchers also made observations in a note form about what had transpired visually in the classroom, which they were unable to record on the audio-tape due to the unreliability of electricity.

\section{Results and Discussion}

\subsection{Prevalence of code-switching}

The findings indicated that code-switching was more prevalent during the lessons of content subjects than English lessons, particularly in Biology and Home Economics where certain concepts needed to be clarified in the native language. For instance, the transcription of the Biology lesson on 'filtration' shows that in a single lesson of 40 minutes, there were 205 sentences made up of 2,700 words excluding inaudible words. Out of these words, there were 1,751 words in English and 949 code-switched Setswana words. The longest sentence contained 44 words with nine words in English and 35 in Setswana.

Also, during a single Home Economics lesson of 35 minutes on 'design elements and principles', there were 211 sentences made up of 3,195 words. The teacher used two thousand seven hundred and three $(2,703)$ words in English and 495 words in Setswana. In this lesson, the researchers noted 198 instances of code-switching, making up $15 \%$ of the discourse. The longest sentence in the discourse contained 30 words out of which 13 (44\%) were in English and 17 (56\%) in Setswana.

The History lesson, in contrast, showed a different picture from the other two content subjects. The lesson was a single period lasting 35 minutes. The transcription contained 194 sentences comprising 2, 842 words. Two thousand seven hundred and eighty eight $(2,788)$ of the words were in English, while 54 were in Setswana. The data show that instances of code-switching comprised only $10 \%$ of the total discourse. In the lesson the longest sentence contained 33 words, and only $3(9 \%)$ of them were code-switched. It was observed that code-switching to Setswana was done at the discourse initiation stage, for greetings and for explaining procedures; but as the lesson progressed, the teacher switched back to English and stuck to it until the end of the lesson.

Like History, there was minimal code-switching during the English Language lesson. For instance, in the English Language lesson which was a single period lasing 40 minutes, there were 110 sentences comprising a total of 1, 395 words. These were the utterances of the teacher and the learners, which excluded the parts that were read from the comprehension passage. From these words, there were only four instances of code-switching in the form of single words or phrases, which accounted for only $0.6 \%$ of the discourse. What is interesting is that even when the teacher initiated the discourse by greeting the class in Setswana, the learners responded in English.

\subsection{Subject specific code-switching}

\subsubsection{Biology}

The Biology lesson shows that switching to Setswana was continuously done throughout the lesson; that is, during the introduction, development and right up to the conclusion. The data also show that as the lesson got more complex, so too was the frequency of code-switching. The researchers observed that in many instances code-switching occurred within and between the sentences, which involved borrowing clauses, phrases or using single words from the mother tongue in order to reinforce the understanding of the subject matter. To show how code switching was used at the initial stage of the lesson on 'filtration', the following excerpt is cited: 


\section{Extract 1}

Teacher: Dumelang. (Hello!)

Class: Ee mma. (Yes, madam)

Teacher: A re tsweleleng bagaetsho.... (Please let us continue) We were discussing about excretion, specifically in relation to the nyphron. Gore (That is) how does the nyphron perform or what is the function of the nyphron in relation to formation? And remember I told you that it is very important for you to know the structure of the nyphron. Re a utlwana? (Do we understand each other?)

\section{Class: Ee mma. (Yes madam)}

Teacher: It is important for you to know the structure of the nyphron and again it is important for you to be able to know the functions of those general parts of the nyphron, not forgetting the reasons why it is necessary for the pressure to be high within the kidney. Gakere? (Isn't it?)

Class: (Some of them) Ee. (Yes)

Teacher: Yes, ketlhalositse hela gore (I only explained that) when the blood gets into the kidney, and especially around the gonerius, e e leng gore (that is) that is a group of capillaries, we expect the pressure to be a bit high, especially for the filtration of the liquid parts. Gakere? (Isn't it?)

From the above extract, it seems starting the lesson by greeting the learners in their native language is intended to build a friendly atmosphere, which has the effect of creating linguistic and ethno-cultural solidarity. The use of the word 'bagaetsho' (literally meaning those of us from the same place) evokes a sense of 'togetherness' or 'inclusivity', which immediately solicits the attention of the learners. Also, the emblematic use of 'ga ke re' establishes a pragmatic contact between the teacher and the class and by so doing helps to sustain the flow of classroom discourse. In the extract, the use of the lexical item 'ga ke re' does not have a specific linguistic denotation but is used rhetorically to find out whether the learners are paying attention or not. Because of its frequent use that borders on habit, at times the learners simply choose to remain silent, or responded affirmatively even if they did not fully understand the teacher. Arthur (2001, p. 62) prefers to call the use of these tag switches "a chorus of minimal responses", that is, switches which occur mechanically and are often used to create an impression that learning is taking place.

As the biology lesson developed, the researchers observed that the teacher resorted to more code-switching from English to Setswana, particularly at the inter-sentential level. There was also a frequent borrowing of words from the target language (e.g. lymphoma, hormone, patching), and generally the teacher used code-switching to emphasize, clarify or to knit together the discourse. To show how code-switching was increasingly used during the development of the lesson, we reproduce below an extract from the middle of the lesson:

\section{Extract 2}

Teacher: So, ha oakanya lego phechiwa jaana ke gore ore bolelela gore... lymphoma hago tsileng go pechiwa teng (So when you think of patching it means you are telling us that it is going to be patched). Le gone (Even then) you are talking about a cell e e leng gore (which is) is... is... something that cannot be a little high. So, le gone o phecha selo se o sa se boneng ka matho jang (how can you patch something you cannot see)?

Learner: (Indecipherable answer)

Teacher: Waii... (Expression of disapproval) nnyaya (No), kana jaanong a re riana (now let's say)...ka (which) hormone... which hormone do you think you're going to be injected ka yone (with it)? Ka haele gore e ya go nna (Because it is going to be a) hormone, e tshwanetse e ye go nna (it should be) ADH. Go raya gore golo gongwe (It may be that) there is a failure in the re-absorption; ka gore (because)...remember what I said ka (about) ADH? Ke rile ( $I$ said) it increases the permeability of a tubule because....

The extensive use of code-switching in the lesson by the teacher answers affirmatively the first research question which asks the extent to which code-switching is prevalent in the curriculum. As can be seen from the extract above, the switches are not only a manifestation of 'floor-holding', that is, filling the gap with the native language in order to achieve linguistic solidarity and intimacy in the classroom, but are also used to contextualize the meaning of the lesson. Braine (2002) and Canagarajah (2002) strongly support the idea of maintaining contact with the "home" language in a bilingual learning environment, and to recognize the learners' needs to "take their identities, values, and interests with them as they communicate in the academy" (Canagarajah, 2002, p. 37). 
Macaro (2001) also supports the idea of code-switching in an L2 classroom because languages are not neutral at all but are used as conduits of social meaning. This point suggests that when L2 learners study science from their cultural perspective, the scientific mystique and the complex nature and foreignness of the technical terms (e.g. 'nyphron', 'gonerius', 'lymphoma', 'hormone', 'absorption' and 'permeability') are easier to clarify in the learners' mother tongue. But as the data from the other subject disciplines show, the process of code-switching largely depends on the teacher, subject content, knowledge and the skill levels of both the teacher and learners.

What is interesting, though, is that when the teacher reaches the end of her biology lesson, she switches back to Setswana, except for the use of the word 'bell'. Bele e ledile (Has the bell rung)? The learners similarly respond in their native language, Ee mma (Yes madam), and the teacher then dismisses the class by using a culturally embedded clause: Go siame (It is okay, you may leave for the next class). The manner in which the lesson is terminated suggests that the use of English is viewed by both the teacher and the learners as limited to the classroom only. As soon as formal learning in the classroom is over, the home language takes over as the medium of communication. This is the dilemma of the language policy of the country: English is foisted upon the school system without considering its limited function in the wider community.

\subsubsection{Home Economics}

In this subject the researchers observed that the frequency of code-switching during the lesson on 'design elements and principles' was considerably reduced. At the beginning of the lesson the teacher greeted the class in Setswana and asked the learners in their native language to tidy up the classroom and to open the windows. Like in the biology lesson, greeting the learners in their native language acted as a bridge to connect the teacher's identity with that of the learners. Like the biology lesson, this lesson was also teacher centred, with the teacher spending much of the time reading from a prepared handout and explaining at intervals important concepts while the learners listened with an occasional 'yes madam'. To illustrate how code-switching was used at the beginning of the lesson, the excerpt below is cited:

\section{Extract 3}

Teacher: So, in design elements ...eh...because you know we are also fashion and fabric students, we are going to be designing certain articles. Eh...eh...or...you can design kana ke (or it is) table cloth or what; it all depends on what you want to design. But ...eh...the design elements eh... for you to start designing, you have to know these design elements... because as you design, you sit down... you use your what? You use your... you use your hands. Gakere (Isn't it)? You cannot just design from the air, you have to sit down and use your hand to draw... or design whatever you...you want to design. So when you look at the handout...the handout that we have, gakere (isn't it) everyone has a handout; gakere (isn't it)?

Class: (in chorus) Yes.

Teacher: So, we are going to use this handout for our discussion. So, the first statement ya re (says) "design is a selection and arrangement of lines... state of both same colour and shape". So when you design, it seems you have to think of the lines. Gakere (Isn't it)?

Class: (some) Yes.

In this excerpt, the teacher largely confines herself to the use of the target language, probably because of the nature of the subject content or perhaps the teacher feels confident enough to conduct most of the lesson in English. The teacher's repeated use of the phrase gakere (which appears to result from habit) is a rhetorical term intended to find out whether the learners are paying attention or not. The teacher's attempt to stick to English is also reflected in the following extract during the development of the lesson:

\section{Extract 4}

Teacher: So, if you use a v-neck line, a v-neck line meets here (demonstrates with her hands). So if you are somebody with a very short neck, heh! (No equivalent English translation) With a short neck, heh! My neck is short... heh! So, then it means if I wear something like this [demonstrates with her hands] a curved line neck like that or a........necklace like that [demonstrates with her hands], what is going to happen?

Class: (silent)

Teacher: My neck is going to appear even very short, and you'll...like this [postures using her neck] Wa bona! Ee! (You see! Yes.) But if you wear something se e leng gore (which is) ... is v-like that [demonstrates] then your neck will appear ... longer. Gakere o bona gore (Isn't it that you can see) this is where these lines meet ... o a bona? (Do you see?) My neck will look longer. Ee! Ke a utlwala? (Am I being understood?) 
What is clear from extract 4 is that, in spite of the teacher's attempt to conduct the lesson in English, she could not resist the temptation to switch to the native language perhaps because it was necessary to use the linguistic choices available to the learners (Edstrom, 2006). This brings us to the second research question: Is the use of code-switching in teaching and learning at senior secondary school in Botswana due to a lack of proficiency in English? Although so far there is no sufficient data and tested findings to support the claim that teachers with a low proficiency in the target language often engage in code-switching (Van der Meij \& Zhao (2010), the researchers' observation about the way the Biology and Fashion and Fabric teachers spoke is that they did not seem to have a complete mastery of the target language.

In the first extract, the biology teacher says "we are discussing about excretion". Although 'discussing about' is often used in spoken English, strictly speaking it is incorrect to say 'discuss about': one discusses something, not 'about'. The teacher's second sentence in the same extract: "...the nyphon in relation to formation" does not have the possessive "its", which refers to formation. Later in the same extract, the teacher says "not forgetting the reasons why". Here, the teacher seems to be unaware of the use of the vocative (you) 'do not forget the reasons'. Also the use of "reasons why" is, strictly speaking, ungrammatical. It is better to use either of the two, that is, 'the reasons for', or why it is necessary for the pressure to be high.

The other observation is that even though the Fashion and Fabric teacher uses English far more than the Biology teacher, she, too, shows signs of limited proficiency in the language. For instance, extracts 3 and 4 show that the teacher is struggling to put across her message: her speech is incoherent, hesitant and incomplete in some cases. Although it could be argued that the use of spontaneous hesitations such as 'eh' is more of a personal idiosyncrasy than lack of proficiency, the researchers' observation of the whole lesson was that she lacked fluency in her communication. Also, her use of non-verbal communication, particularly the hands, was a compensatory strategy intended to clarify what her verbal communication could not accomplish, a strategy which is often used by second language speakers who have not yet fully mastered the target language.

If we use the prevalence of code-switching in Biology and Home Economics as reflecting the practice in most of the content subjects, then it can be surmised that code-switching (see research question 4) negates Botswana's language policy which stipulates that English should be the sole language of education at secondary school level. On this issue, however, the researchers need to reiterate Jorgensen's (2006) observation that as long as people have access to alternative languages, they are likely to employ them when the need arises. What seems to be the problem is that it is not so much about 'undermining' the language policy of the country but that there is a discrepancy between the prescription of the language policy in education and classroom practice.

\subsubsection{History}

Throughout this lesson, just like in all other lessons tape recorded, the researchers noted a deafening silence by the learners. When the researchers asked the teachers later after tape recording their lessons why the learners had remained silent during the lesson, the teachers maintained that the students were not confident enough to speak in English. This takes us back to the third research question: Is code-switching consistent with the practical realities of the classroom situation? To answer this question, let us look at the learners' responses during the history lesson on the colonization of the South African Cape by the Dutch.

\section{Extract 5}

Teacher: To start with, from which country are the Dutch?

Class: (silent)

Teacher: The Dutch are from which country? If people are referred to as the Dutch, they are from? Yes, Naledi? (Not the real name of the student and so are all other learners' names mentioned in the study)

Naledi: Holland.

Teacher: They are from Holland... Holland. This country ... Holland is also known as Holland or?

Thuso: The Netherlands

Teacher: Ok, whenever someone has to drive a very long distance or you're just there as a passenger, eh... the chances that you're going to get tired... maybe travelling from here to Gaborone... travelling from here to Kasane, Maun... (These are towns and villages in Botswana) five hundred or more kilometers...you are bound to get tired. Ee... (Yes) that's why batho ba bo (people from) road transport...they advise people to have some eh... points where they may rest. So we're saying that these people ... as they sailed from Europe to the Far East, they faced these problems of tiredness. Also there was a problem of the outbreak of scurvy... What is scurvy?

Class: (silent) 
Teacher: What is scurvy?

Class: (silent)

Teacher: We agreed that these people got tired because the journeys were really long. The other problem was that there was an outbreak of the disease, and bolwetsi jo ke eng? (What is the illness?)

Class: (silent)

Mpho: (mumbling something)

Teacher: Will you please raise your voice!

Mpho: This is caused by lack of vitamins.

In the excerpt above, the learners are reluctant to answer the question in English and decide to remain silent even after the teacher has given them a clue. Could the silence be construed to mean that the learners were not confident enough to speak in English, as the teachers claimed? The history excerpt above suggests this may have been the case because when the teacher asked the same question in the learners' "heritage" language, one of them gave an appropriate answer that scurvy is caused by a lack of vitamins. In this case, the use of the learners' "home" language is in response to a practical reality of the classroom situation, which demands a consideration of the learners' English competence.

However, it could also be interpreted that the silence of the learners is a question of the power relations between the teacher and the learners, especially when the learners are not given a meaningful chance to express their views. McNay (2000, p. 44), for example, supports the view that the existence of two or more language systems, especially where there is a foreign language which has an 'official' language status, often brings about complex issues of power relations between the speakers of the target language. The lack of 'voice' by the learners throughout all the recorded lessons in this study is probably a result of this problem, and is an indictment of the pedagogic approach which reduces the learners to mere spectators, instead of being active participants who are capable of constructing knowledge on their own.

\subsubsection{English language}

As noted above under section 5.1 dealing with the prevalence of code-switching in different subjects, there was hardly any code-switching when the class was doing a comprehension passage on "Man and Animals". Only four instances of code-switching involving single words or phrases were observed. To show how the teacher conducted the English lesson without resorting to code-switching, the researchers reproduce below the introduction which encapsulates the tone of the whole lesson.

\section{Extract 6}

Teacher: Okay, I asked you to read this paper over the week-end and I believe you did. Remember ... and I want us to look at the question, particularly the vocabulary section in question eight, and after that we are going to look at the summary question and identify the summary points. Basically, we are going to identify the summary points after we have looked at the vocabulary exercise. Are we together?

In this excerpt, and indeed in the rest of the lesson, there is hardly any code-switching to the native language of the learners, unlike in the other subjects where code alternation within and across sentences was pervasive. What is also evident (scrutinize extract 6) is that the English language teacher appears to be more competent in the target language than the other teachers cited earlier. The excerpt shows that the English teacher, perhaps because he is specialised in the subject, is fluent and provides a useful model for the learners to emulate. The need to be competent in the target language is consonant with Krashen's (1988) highly influential theory of the "natural approach", which suggests that what matters most in second language learning is comprehensible "input". If the input is clear, regardless of whether the teacher is a first or second language speaker, the learners will understand the message without having to resort to code-switching.

\section{Limitations}

In an ethnographic study such as this one which requires the researchers to describe and interpret the data, there will always remain room for different interpretations especially because the power to judge a phenomenon depends on the ideological inclination of the researchers. The other problematic issue is the sheer size of the study and the huge amount of data involved. In the researchers' attempt to understand the prevalence of code-switching in Botswana's ESL classrooms, many research subjects were involved. This made it difficult to focus on research subjects who typify the whole research group. Besides, a selection of code-switching practices 
in Biology, Home Economics, History and English may not necessarily reflect what goes on in the rest of the other subjects.

Another problematic issue is that virtually all the data reported in this study concern code-switching by teachers. All the tape recorded lessons show that learners were not given an ample opportunity to converse either in the target language or in their home language. The limited data available on students' code-switching behaviour means that there is still inadequate information about the pervasiveness of the problem. Similarly, the study does not attempt to establish the effect of code-switching on the learners' academic performance. This issue is critical because the raging debate on whether code-switching in the classroom is beneficial or not can be put to rest if there is clear research evidence for or against its use.

\section{Implications}

In spite of the limitations, this study has a number of implications. The first thing that emerges from this study is that code-switching cannot be wished away. As long as learners and teachers live in a community which is bi- or multilingual, there will always be need to use alternative language codes which can best express their ideas. In this study, it has been shown that code-switching is used in teaching almost all the subjects, especially content subjects. An analysis of the lessons has shown that there is an underlying problem in the teachers' English proficiency. It is, therefore, prudent to find a solution which can provide "enough space" for code-switching (Stroud, p. 46) so that it can be duly recognized as a legitimate pedagogic approach.

As this study has shown, code-switching happens willy-nilly in the secondary school curriculum in Botswana. The implication of this is that teachers in both primary and secondary schools need to adapt to the knowledge and skill levels required for code-switching. Cook (2001) suggests that teacher training institutions need to design their teacher preparation programs so that they can add code-switching techniques as part of the repertoire for teaching. Adendorff (1996) similarly proposes a training program in which 'consciousness-raising' is a priority if teachers are going to understand the role of code-switching in the curriculum. One of the critical issues he raises is to sensitize teachers to the fact that languages carry a social meaning and that the learners' heritage language can be used as a window through which meaningful knowledge can be constructed in the classroom out of their primary experience and culture.

\section{Conclusion}

This study has shown that, although Botswana's language policy in education favours the use of English for learning and teaching throughout the secondary school curriculum, code-switching occurs in many classroom discourses, especially in content subjects. Unlike the other previous studies that have not found a link between code-switching and proficiency in the target language, in this study the teachers who code-switched tended to lack a full mastery of the target language.

From an administrative point of view, those teachers who code-switched, irrespective of the subject they taught, contravened the language in education policy which states that English is the official language for the teaching of all subjects (apart from Setswana and French) from the second year of primary school up to university. The violation of the language policy is, however, understandable because code-switching in the classroom is in response to the learners' functional needs, such as the need to bridge the gap between their limited competence in the target language and the need to allow them to construct knowledge through the experience of their primary language and culture.

Arising from the findings of this study, it is recommended that the language in education policy be revised, at least partially, in order to deal with the practical realities of the classroom situation in which the home and the target language have a mutually supportive role. By using both languages in the classroom, it may be possible to curb the disturbing observation that learners are treated as passive participants whose views do not matter in the learning process.

A final word about this study is that the findings do not in any way suggest a jettisoning of the official language policy in education, but simply provide an insight into the current learning and teaching culture. If public policy is going to institutionalize code-switching, like what happens in all other private and public domains in Botswana, then both teachers and learners will need to be sensitized to the value and limitations of code-switching. In particular, as Edstrom (2006, p. 290) puts it, teachers will need to adjust their didactic approach as "a first step towards understanding one's linguistic and pedagogical choices in the classroom".

\section{References}

Adendorff, R. (1993). Code-switching among Zulu speaking teachers and their pupils: Its functions and implications for teacher education. Southern African Journal of Applied Language Studies, 2 (1), 3-26. 
Adendorff, R. (1996). The functions of code-switching among high school teachers and students in KwaZulu and implications for teacher education. In K. M. Bailey \& D. Nunan (Eds.). Voices from classroom: Qualitative research in second language learning (pp. 388-406). Cambridge: Cambridge University Press.

Akindele, D. F., \& Letsoela, M. (2001). Code-switching in Lesotho secondary and high schools. BOLESWA Educational Research Journal, 18, 83-100.

Arthur, J. (2001). Code-switching and collusion: Classroom interaction in Botswana primary schools. In M. Heller \& M. Martin-Jones (Eds.). Voices of authority: Education and linguistic difference (pp. 57-75). Westport: Ablex Publishing.

Auer, P. (1998). (Ed.). Code-switching in conversations: Language, interaction and identity. Cambridge, U.K.: Cambridge University Press.

Botswana Government. (1994). Botswana Government White Paper No. 2. Gaborone: Government Printer.

Bourdieu, P. (1977). L'economie des echanges linguistiques. Langue Francaise, 34, 17-34. http://dx.doi.org/10.3406/lfr.1977.4815

Braine, G. (2002). Academic literacy and the nonnative speaker graduate student. Journal for English for Academic Purposes, 1 (1), 59-69. http://dx.doi.org/10.1016/S1475-1585(02)00006-1

Butler, J. (1997). Excitable speech: A politics of the performative. New York \& London: Routledge.

Canagarajah, S. (2002). Multilingual writers and the academic community: Towards a critical relationship. English for Academic Purposes, 1 (1), 29-44. http://dx.doi.org/10.1016/S1475-1585(02)00007-3

Canagarajah, S. (2005). Critical pedagogy in L2 learning and teaching. In E. Henkel (Ed.). Handbook on research on second language teaching and learning (pp 29-39).

Cook, V. (2001). Using the first language in the classroom. Canadian Modern Language Review, 57, 399-423. http://dx.doi.org/10.3138/cmlr.57.3.402

Cook, V. (2002). Portraits of the L2 User. Clevedon: Multilingual Matters.

Edstrom, A. (2006). L1 use in the L2 classroom: One teacher's self-evaluation. Canadian Modern Language Review, 63, 275- 292. http://dx.doi.org/10.3138/cmlr.63.2.275

Eldridge, J. (1996). Code-switching in a Turkish secondary school. ELT Journal, 50 (4), 303-311. http://dx.doi.org/10.1093/elt/50.4.303

Gabrielatos, C. (2001). L1 use in ELT: Not a skeleton, but a bone of contention. TESOL Greece Neewsletter, 70, 6-9.

Gal, S. (1989). Language and political economy. Annual Review of Anthropology, 18, 345-367. http://dx.doi.org/10.1146/annurev.an.18.100189.002021

Garafanga, J. (2001). Linguistic identities in talk-in-interaction: Order in bilingual conversation. Journal of Pragmatics, 33, 1901-1925. http://dx.doi.org/10.1016/S0378-2166(01)00008-X

Gila, B. N. (1995). An investigation into the role of code-switching in classroom interaction in Transkei junior secondary schools. M.A. thesis. Durban: University of Natal.

Gumperz, J. J. (1982). Discourse strategies. Cambridge: Cambridge University Press. http://dx.doi.org/10.1017/CBO9780511611834

Hussein, R. F. (1999). Code alteration among Arab college students. World Englishes, 18 (2), 281-289. http://dx.doi.org/10.1111/1467-971X.00141

Hymes, D. (1974). Foundations in Sociolinguistics: An ethnographic Approach. London: Tavistock Publications Ltd.

Jorgensen, J. N. (2005). Plunlingual conversations among bilingual adolescents. Journal of Pragmatics, 37, 391-402. http://dx.doi.org/10.1016/j.pragma.2004.10.009

Kamwangamalu, N. M. (2000). The state of code-switching research at the dawn of the new millennium: Focus on Africa. Southern African Linguistics and Applied language Studies, (SAALA), 18, 59-71

Kieswetter, A. (1995). Code-switching amongst African high school pupils: Occasional paper. African Linguistics, No. 1. Johannesburg: University of the Witwatersrand.

Krashen, S. (1988). Second Language Acquisition and Second Language Learning. New Jersey: Prentice Hall. 
Lawson, S., \& Sachdev, I. (2000). Code-switching in Tunisia: Attitudinal and behavioural dimensions. Journal of Pragmatics, 32, 343-361. http://dx.doi.org/10.1016/S0378-2166(99)00103-4

Letsebe, H. (2002). A study of teachers' explanations and pupils' views on code-switching in selected schools in Gaborone, Tlokweng and Mogoditshane. M..Ed. thesis. Gaborone: University of Botswana.

Liebscher, G., \& Dailey-O'Cain, J. (2005). Learner code-switching in the content-based foreign language classroom. Modern Language Journal, 89, 234-247. http://dx.doi.org/10.1111/j.1540-4781.2005.00277.x

Macaro, E. (2001). Analysing student teachers' code-switching in foreign language classrooms: Theories and decision making. Modern Language Journal, 85, 531-548. http://dx.doi.org/10.1111/0026-7902.00124

Mafela, L. (2009). Code-switching in Botswana History classrooms in the decade of education for sustainable development. Language matters: Studies in the languages of Africa, 40 (1), 56-79.

McMillan, J. H., \& Schumacher, S. (1993). Research in Education: A conceptual understanding. New York: Harper Collins.

McNay, L. (2000). Gender and agency: Reconfiguring the subject in feminist social theory. Maldem, Mass: Polity Press.

Milroy, L., \& Muysken, P. (1995). Introduction: Code-switching and bilingualism research. In L. Milroy \& P. Muysken (Eds.), One speaker two languages: Cross-disciplinary perspectives on code-switching (pp. 1-14). New York: Cambridge University Press.

Molosiwa, A.A. (2006). Literacy instruction in an examination-oriented environment: Perceptions of secondary school teachers in Botswana. PhD thesis. Michigan: Michigan State University.

Myers-Scotton, C. (1993). Social motivations for code-switching: Evidence from Africa. Oxford: Clarendon Press.

Ni, Q. (2007). Traditional Chinese culture and ELT. SAAL Quarterly, 80, 2-11.

Numan, D., \& Carter, D. (2001). Teaching English to Speakers of Other Languages. Cambridge: Cambridge University Press.

Nyathi-Ramahobo, L. (2004). The language situation in Botswana. In R. B. Baldauf Jr \&R. B. Kaplan (Eds.), Language planning and policy in Africa. Vol. 1: Botswana, Malawi, Mozambique, and South Africa (pp. 21-78). Clevedon; Multilingual Matters.

Sebba, M., \& Wootton, T. (1998). We, they and identity: Sequential versus identity-related explanation of code-switching. In P. Auer (Ed.), Code-switching in conversation: Language, interaction and identity. Cambridge, U.K.: Cambridge University Press.

Skiba, R. (1997). Code-switching as a countenance of language interference. The Internet TESL Journal, 3, 10. Retrieved from http://iteslj.org/Articles/Skiba-Code-switching.html

Stroud, C. (1998). Perspectives on cultural variability of discourse and some implications for code switching. In P. Auer (Ed.), Code-switching in conversation: Language, interaction and identity (pp. 321-348). Cambridge, U.K.: Cambridge University Press.

Stroud, C. (2004). The performativity of code-switching. International Journal of Bilingualism, 8 (2), 145-166. http://dx.doi.org/10.1177/13670069040080020301

Trudgill, P. (2000). Sociolinguistics. London: Penguin.

Van Der Meij, H., \& Zhao, X. (2010). Code-switching in English Courses in Chinese Universities. Modern Language Journal, 94 (3), 396-411. http://dx.doi.org/10.1111/j.1540-4781.2010.01090.x 